\title{
An Empirical Study of Factors Influencing the Intention to Use SNS App
}

\section{-The Case of Facebook}

\author{
Yi-Wen Fan ${ }^{1}$, Juo-Tzu Tseng ${ }^{1}$, Yu-Hsien Fang ${ }^{1}$, Zheng-Yen $\mathrm{Li}^{1}$, Yea-Huey Su${ }^{1}$ \\ ${ }^{1}$ Department of Information Management, National Central University, I1-213, No.300, Zhongda Rd., Zhongli District, \\ Taoyuan City 320, Taiwan (R.O.C.) \\ Correspondence: Juo-Tzu Tseng, Department of Information Management, National Central University, I1-213, No.300, \\ Zhongda Rd., Zhongli District, Taoyuan City 320, Taiwan (R.O.C.).
}

Received: February 9, 2017

doi:10.11114/bms.v3i1.2258

\author{
Accepted: March 2, 2017 \\ Online Published: March 5, 2017 \\ URL: https://doi.org/10.11114/bms.v3i1.2258
}

\begin{abstract}
Mobile Internet is coming. The social networking site application (SNS app) has become an important portal for users accessing social networking services. Based on the point of view of existing social network users, this study integrates the technology value-based adoption model and social influence to propose a framework to investigate factors influencing the use intention of the SNS app. A sample of 223 subjects surveyed from Facebook, it was found that user's perceived value regarding the SNS app positively affects the use intention of the social networking app. Usefulness and Technicality provided by SNS app positively affects perceived value of the app. In addition, user perceived social influence also positively affects the use intention of the social networking app. Results not only advance knowledge related to social network research, as well as provide practical advice to social networking companies. They also suggest how to attract users to continually participate in social networks. Increase activeness and stickiness is critical for social network companies to facilitate long-term development.
\end{abstract}

Keywords: SNS app, use intention, technology value-base adoption model, social influence

\section{Introduction}

With the rapid advancement in information and communication technology (ICT), social networking sites (SNSs) have seen rapid growth and become a global phenomenon (Pornsakulvanich \& Dumrongsiri, 2013). SNSs are an important topic, and they can help preserve our social relationships (Bohn, Buchta, Hornik, \& Mair, 2014). The development of many mobile devices and applications has increased the convenience in the daily lives of many people (Chaouali, 2016). SNS apps are the some of the most popular and widely used on mobile devices and smartphones (Wu, Tao, Li, Wang, \& Chiu, 2014; Nikou \& Bouwman, 2014). The adoption of smartphones to browsing SNSs has been a phenomenon (Wu et al., 2014). Through mobile apps, anyone can use the mobile Internet or wireless services to access SNSs (Zheng \& Lee, 2016).

Mobile social networking sites (MSNSs) are more time sensitive and location sensitive than social networking sites (Kaplan, 2012). Users can use mobile and wireless networks to extend the reach of SNSs and generate more interactive opportunities (Arnaboldi, Conti, \& Delmastro, 2014). Nikou and Bouwman (2014) show that MSNs applications are some of the most popular applications.

Therefore, determining how to engage users in community service, increase activity, and increase retention can help the long-term development of the SNS industry. In this study, we investigate SNS users to obtain deeper understanding of use intentions and to explore the most influential factors.

Most of today's SNSs offer the three following features in some form: (1) allowing users to construct a public or semi-public image within a limited system, (2) permitting users to connect with a group of users who are willing to share messages, and (3) allowing users to observe and trace linkages established by others in the community system back to themselves (Boyd \& Ellison, 2007). SNS users send and receive information by posting, sharing, and messaging through computer-mediated communication. SNSs are used to transmit information and feelings between users.

The technology acceptance model (TAM) has been used to explore intentions to adopt new technology. The characteristics of a system include the users' perceived usefulness and perceived ease of use, and the final effect is the 
behavioral intention to use the technology (Davis, 1993). However, the human-based of interactions and mobile technologies (e.g., mobile SNS), TAM may not provide accurate or sufficient understanding of user intention (Nikou \& Bouwman, 2014). Prior literatures investigated technology for work purposes, and the users were mostly employees within an organization. Therefore, this study follows the guidelines of H. Kim, Chan, and Gupta (2007) and uses a value-based adoption technology model. The model is explores the benefits and sacrifices of new technology according to users based on the formation of perceived value and the use intention of an SNS.

Social influence provides a complementary view of attitudes toward a new technology (Venkatesh \& Davis, 2000; Moore \& Benbasat, 1991). The group relationships in SNSs influence the use intention through social factors (Cheung, Chiu, \& Lee, 2011). The behavior of individuals is likely influenced by others around them, and obedience or compliance with the actions of others is called social influence or the bandwagon effect (Jahoda, 1959). SNS apps can be seen as a new type of information technology, and recommendations from friends and family can affect use intention. Therefore, this study explores social influence in the research model, including whether the willingness of individuals to use an SNS app is influenced by others.

\section{Literature Review}

\subsection{Technology Value-Based Adoption Model}

According to $\mathrm{H}$. Kim et al. (2007), the usage of new technology for individual purposes is different from the work-demand-oriented usage discussed for the traditional TAM. Therefore, specific attention is needed for the economy, marketing, accounting, and financial domains. Analyzing the customers' perceived value is particularly important. The information systems and marketing literature shows that perceived value is one of the most significant factors in use intention (B. Kim \& Han, 2009; Shin, 2009; Anckar, Carlsson, \& Walden, 2003). According to the utilitarian view, customers' perceived product value is a combination of acquired value and transactional value (Thaler, 1985). Customer value theory divides product value into functional, social, emotional, novel, and situational value (Sheth, Newman, \& Gross, 1991). H. Kim et al. (2007) explore the factors that influence use intention of mobile networking from the customer's point of view by constructing a technology value-based adoption model, which combines the use of technology with the exploration of value. Ngai (2007) used the technology value-based adoption model to examine the value of mobile networks and communication technology in a new form of economic and market research to understand customer choices and decisions, as well as to maximize the value of user behavior.

The technology value-based adoption model points out that perceived value is affected by benefit and sacrifice. Perceived value has been defined as the evaluation of a product's overall utility (Zeithaml, 1988). Benefit is divided into external perceived benefit (e.g., usefulness) and internal emotional benefit (e.g., enjoyment). These two types of perceived benefit have a positive impact on the perceived value by the user. Sacrifice is divided into money sacrifice (e.g., perceived fees) and non-money sacrifice (e.g., technicality). Both types of perceived sacrifice are negatively correlated with perceived value. Finally, the perceived value by the user has a positive impact on the user's intention to adopt a new technology.

In this study, the perceived value of SNS apps is defined after asking volunteers to use the app, who were then asked to evaluate the app overall. If users believe the app has high value for meeting their social demands, then they will be more likely to use it. Therefore, we predict the following:

H1. The perceived value of the SNS app positively influences the use intention of the app.

H2. The usefulness of the SNS app positively influences the perceived value of the app.

H3. Enjoyment of the SNS app positively influences the perceived value of the app.

H4. Technicality of the SNS app positively influences the perceived value of the app.

\subsection{Social Influence}

Interpersonal interactions and the social influence of members of SNSs are a necessary part of SNS studies (Dumrongsiri \& Pornsakulvanich, 2010). Social influence refers to how an individual is influenced by the behavior of others in a social network in order to conform to social behavior patterns (Venkatesh \& Brown, 2001). Social influence can be achieved through three different processes: compliance, internalization and identification (Kelman, 1958). Compliance refers to the occurrence of a feeling that social members wanting an individual to perform a particular act, and that member of the social have the power to reward or punish for them (Venkatesh \& Davis, 2000). Internalization refers to an individual accepting the influence because they think it helps to increase their self-value to achieve their goals (Dholakia, Bagozzi, \& Pearo, 2004). Identification refers to an individual establishing or maintaining a relationship with another person or group and to adopting his or her action or opinions (Kelman, 1958). 
There are two kinds of social influence: informational social influence and normative social influence (Deutsch \& Gerard, 1955). Informational social influence refers to an individual obtaining real evidence from others, believing the information, and considering the information provided is sufficiently believable. Normative social influence refers to an individual wanting identity with other people, so they follow the expectations of the group, they do not think about the reliability of the information, and they accept all of it. Information social influence occurs through the process of internalization of individual behavior, but normative social influence occurs through the process of compliance and identification.

Social influence is one of the most important factors in exploring user acceptance of the mobile SNSs (Nikou \& Bouwman, 2014). The integrated UTAUT (unified theory of acceptance and use of technology) points out that social influence is one of the main factors that affect the use intention of technology (Venkatesh, Morris, Davis, \& Davis, 2003). Lu et al. (2005) propose that social influence is also one of the factors in the usage of wireless mobile technology. Social influence has also been used to study the adoption intentions of an advanced mobile service (López-Nicolás, Molina-Castillo, \& Bouwman, 2008) and the intention to participate in a virtual Facebook community (Cheung et al., 2011).

In this study, defined social influence as a user's belief that they should use the SNS for the consideration of people who are important to them. When most of a user's friends and using an SNS app, he or she is more likely to be encouraged to use the SNS app through a process of compliance or identification. Therefore, in our study we hypothesized the following:

H5: Social influence positively influences use intention of the SNS app.

The study offers the research model as Figure 1.

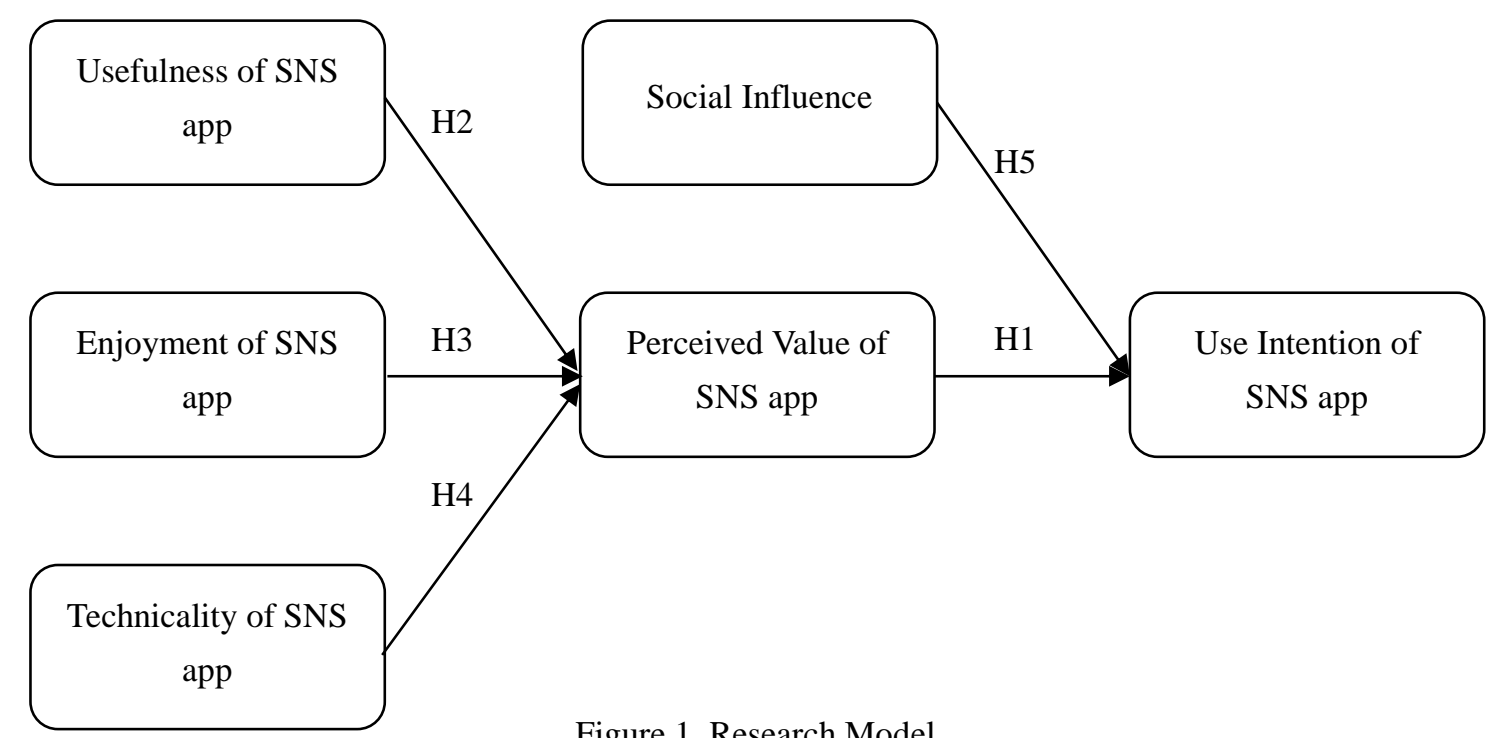

Figure 1. Research Model

\section{Research Methods}

In order to validate the research model, this study examines the most popular SNS in Taiwan as a survey source Facebook. The sample is collected in Taiwan in May 2015 using an online questionnaire. Facebook offers an online social interaction platform for users to update about their individual situations, send messages, posts, share photos and images, and "like" what their friends post. Taiwan's Facebook averaged at 18 million monthly active users, 16 million mobile monthly active users, 13 million daily active users, and 12 million mobile dives user (Udndata, 2016). A sample of Facebook users was surveyed for this study.

This research uses AMOS and SPSS statistics tools analysis data. We use SEM (structural equation modeling). We use statistics, reliability and validity analysis, and SEM analysis. The research items are coded on a five-point Likert scale ranging from strongly disagree (1) to strongly agree (5).

\section{Data analysis and Discussion}

\subsection{Descriptive Statistics Analysis}

As many as 223 subjects participated in the survey. The demographic statistics (Table 1) shows more men (60.09\%) than women $(39.91 \%)$. The age of the respondents is mostly 15-34 years old (88.35\%). Almost all respondents have 
higher education (university, college, and graduate school). Most of the respondents are students, service workers, information technology workers, and public servants.

Table 1. Demographic statistics data $(\mathrm{N}=223)$

\begin{tabular}{llrc}
\hline \multicolumn{1}{c}{ Measure } & \multicolumn{1}{c}{ Items } & Frequency & Percentage \\
\hline \multirow{2}{*}{ Gender } & Male & 134 & $60.09 \%$ \\
& Female & 89 & $39.91 \%$ \\
Age & $<14$ & 1 & $0.45 \%$ \\
& $15-24$ & 124 & $55.61 \%$ \\
& $25-34$ & 73 & $32.74 \%$ \\
Education & $>35$ & 25 & $11.20 \%$ \\
& Middle school or below & 1 & $0.45 \%$ \\
& High school & 4 & $1.79 \%$ \\
& University & 116 & $52.02 \%$ \\
& Graduate school or above & 102 & $45.74 \%$ \\
& Student & 143 & $64.13 \%$ \\
& Service industry & 26 & $11.66 \%$ \\
& Information technology industry & 16 & $7.17 \%$ \\
& Public servant & 13 & $5.83 \%$ \\
& Construction Industry & 9 & $4.04 \%$ \\
& Financial industry & 6 & $2.69 \%$ \\
& Others & 10 & $4.48 \%$ \\
\hline
\end{tabular}

\subsection{Common Method Variance}

The common method variance (CMV) is the "variance that is attributable to the measurement method rather than to the constructs the measures represent" (Podsakoff, MacKenzie, Lee, \& Podsakoff, 2003). To avoid any potential CMV in the results, we adopted Harman's single-factor test (Harman, 1967). The method has been used in many studies (Podsakoff, Todor, Grover, \& Huber, 1984; Green \& Organ, 1973). The method loads all 20 items from each of the constructs into an exploratory factor analysis (EFA) and tests the un-rotated factor analysis results (Podsakoff and Organ, 1986). In the test results, we found that three factors were extracted. The first factor's explanatory power is $47.327 \%$. Because the power is less than 50\%, the result is not significant common method biases.

This study uses confirmatory factor analysis with a single factor to retest (Mossholder, Bennett, N., Kemery, \& Wesolowski, 1998). The method loads all items to single factor to testing, and it is not over 0.5 for all the items. The analysis is not a general factor. The results indicate that CMV does not occur. The goodness-of-fit indices of the single-factor model are $\chi 2 / d f=5.545$, goodness-of-fit $(\mathrm{GFI})=0.674$, comparative fit index $(\mathrm{CFI})=0.727$, root mean square error of approximation (RMSEA) $=0.143$, and adjusted goodness-of-fit $($ AGFI) $=0.598$. The standard is not significant $(\chi 2 / d f<5$ (Bollen, 1989), GFI > 0.80, CFI > 0.90, RMSEA < 0.08 (Browne \& Cudeck, 1993), and AGFI > 0.80 (Scott, 1995)). The result shows that the single factor model and analysis data have a poor fit. In this study, no significant CMV question exists.

\subsection{Measurement Model Analysis}

The research model was tested using SEM with SPSS and AMOS software. The measurement model was used to test and validate the hypotheses. In the first step, the measurement model was estimated using confirmatory factor analysis (CFA) to test the reliability and validity of the constructs. All the items have shown appropriate factor loadings with values greater than 0.5 (Hair, Black, Anderson, \& Tatham, 2005). The results for testing the construct and convergence validity include Cronbach's alpha $(\mathrm{C} \alpha)$, the composite reliability $(\mathrm{CR})$, and the average variance explained (AVE). The values of $\mathrm{C} \alpha$ for all our variables were well above the recommended level of 0.7 (Numally, 1978). Furthermore, the recommended criteria for a scale to be considered reliable indicate that CR should be above 0.7 and AVE should be above 0.5 (Fornell \& Larcker, 1981). The discriminant validity was well above the recommended value (Hair et al., 2005). The results have shown in Tables 2 and Table3. 
Table 2. Factor loading $(\mathrm{N}=223)$

\begin{tabular}{|c|c|c|c|c|}
\hline Constructs & Items & $\begin{array}{l}\text { Factor } \\
\text { loading }\end{array}$ & Average & $\begin{array}{l}\text { Standard } \\
\text { error }\end{array}$ \\
\hline \multirow{3}{*}{$\begin{array}{l}\text { Use Intention of } \\
\text { SNS app (INT) }\end{array}$} & USE1. I am satisfied with using Facebook app. & $0.709^{* * *}$ & 4.07 & 0.74 \\
\hline & $\begin{array}{l}\text { USE2. In the next month, I intend to use the Facebook } \\
\text { app. }\end{array}$ & $0.859^{* * *}$ & 3.70 & 0.84 \\
\hline & $\begin{array}{l}\text { USE3. I would like to introduce Facebook to other } \\
\text { people. }\end{array}$ & 0.822 & 3.69 & 0.82 \\
\hline \multirow{3}{*}{$\begin{array}{l}\text { Perceived } \\
\text { of SNS alue } \\
\text { (VAL) }\end{array}$} & $\begin{array}{l}\text { VAL1. Compared to the effort required, using the } \\
\text { Facebook app is beneficial for me. }\end{array}$ & $0.863^{* * *}$ & 3.48 & 0.83 \\
\hline & $\begin{array}{l}\text { VAL2. Compared to the time required, using the } \\
\text { Facebook app is worthwhile for me. }\end{array}$ & $0.820^{* * *}$ & 3.57 & 0.79 \\
\hline & $\begin{array}{l}\text { VAL3. Overall, using the Facebook app has been greatly } \\
\text { worthwhile. }\end{array}$ & 0.798 & 3.61 & 0.75 \\
\hline \multirow{4}{*}{$\begin{array}{l}\text { Usefulness of } \\
\text { SNS app (USE) }\end{array}$} & $\begin{array}{l}\text { USE1. Using the Facebook app to communicate } \\
\text { remotely can let me communicate more quickly. }\end{array}$ & $0.853^{* * *}$ & 4.00 & 0.82 \\
\hline & $\begin{array}{l}\text { USE2. Using the Facebook app can improve my remote } \\
\text { communication efficiency. }\end{array}$ & $0.858^{* * *}$ & 3.92 & 0.86 \\
\hline & $\begin{array}{l}\text { USE3. Using the Facebook app can increase my remote } \\
\text { communication effectiveness. }\end{array}$ & $0.729^{* * *}$ & 3.81 & 0.86 \\
\hline & $\begin{array}{l}\text { USE4. Using the Facebook app can make it easier for } \\
\text { me to communicate remotely. }\end{array}$ & 0.801 & 4.05 & 0.78 \\
\hline \multirow{3}{*}{$\begin{array}{l}\text { Enjoyment of } \\
\text { SNS app (ENJ) }\end{array}$} & ENJ1. Using the Facebook app is fun for me. & $0.811^{* * *}$ & 3.73 & 0.75 \\
\hline & $\begin{array}{l}\text { ENJ2. Using the Facebook app offers me a lot of } \\
\text { pleasure. }\end{array}$ & $0.880^{* * *}$ & 3.58 & 0.85 \\
\hline & ENJ3. I like Using the Facebook app. & 0.877 & 3.64 & 0.92 \\
\hline \multirow{4}{*}{$\begin{array}{l}\text { Technicality of } \\
\text { SNS app (TEC) }\end{array}$} & TEC1. The Facebook app can be immediately linked. & $0.700^{* * *}$ & 3.74 & 0.94 \\
\hline & $\begin{array}{l}\text { TEC2. The Facebook app can take a short time to } \\
\text { respond. }\end{array}$ & $0.838^{* * *}$ & 3.60 & 0.83 \\
\hline & $\begin{array}{l}\text { TEC3. It is easy to get the Facebook app to do what I } \\
\text { want it to do. }\end{array}$ & $0.659^{* * *}$ & 3.63 & 0.86 \\
\hline & TEC4. The system of the Facebook app is reliable. & 0.611 & 3.44 & 0.84 \\
\hline \multirow{3}{*}{$\begin{array}{l}\text { Social Influence } \\
\text { (SOC) }\end{array}$} & $\begin{array}{l}\text { SOC1. The people who have an impact on my behavior } \\
\text { consider that me using Facebook app is a good choice. }\end{array}$ & $0.766^{* * *}$ & 3.51 & 0.72 \\
\hline & $\begin{array}{l}\text { SOC2. The people who are important to me (friends and } \\
\text { family) consider that I should use the Facebook app. }\end{array}$ & $0.887^{* * *}$ & 3.35 & 0.72 \\
\hline & $\begin{array}{l}\text { SOC3. In general, my community supports me using the } \\
\text { Facebook. }\end{array}$ & 0.749 & 3.63 & 0.76 \\
\hline
\end{tabular}

" $\mathrm{p}<0.05 ;{ }^{* *} \mathrm{p}<0.01 ;{ }^{* * *} \mathrm{p}<0.001$

Table 3. Discriminant validity, average variance explained (AVE), composite reliability (CR), and Cronbach's alpha (C $\alpha$ ) ( $\mathrm{N}=223$ )

\begin{tabular}{cccccccccc}
\hline & AVE & CR & $\boldsymbol{\alpha}$ & INT & VAL & USE & ENJ & TEC & SOC \\
\hline INT & 0.64 & 0.84 & 0.84 & $\mathbf{0 . 7 9 9}$ & & & & & \\
VAL & 0.68 & 0.87 & 0.86 & 0.764 & $\mathbf{0 . 8 2 7}$ & & & & \\
USE & 070 & 0.89 & 0.88 & 0.682 & 0.527 & $\mathbf{0 . 8 1 2}$ & & & \\
ENJ & 0.73 & 0.89 & 0.89 & 0.790 & 0.640 & 0.693 & $\mathbf{0 . 8 5 7}$ & & \\
TEC & 0.50 & 0.80 & 0.79 & 0.699 & 0.529 & 0.509 & 0.662 & $\mathbf{0 . 7 0 7}$ & \\
SOC & 0.64 & 0.84 & 0.84 & 0.708 & 0.710 & 0.545 & 0.699 & 0.607 & $\mathbf{0 . 8 0 3}$ \\
\hline
\end{tabular}


Diagonal elements represent the average variance extracted (AVE), while off-diagonal elements represent the square correlations. For adequate discriminant validity, diagonal elements should be greater than corresponding off-diagonal elements.

\subsection{Structural Model Analysis}

The research model fits results are $\chi 2 / d f=2.49$, goodness-of-fit $(\mathrm{GFI})=0.85$, comparative fit index $(\mathrm{CFI})=0.92$, root mean square error of approximation $($ RMSEA $)=0.08$, and adjusted goodness-of-fit $($ AGFI $)=0.80$. Overall, the results show a good fit. The fit is normally deemed to be very good when $\chi 2 / d f<5$ (Bollen, 1989), GFI $>0.80$, CFI $>0.90$, RMSEA $<0.08$ (Browne \& Cudeck, 1993), and AGFI > 0.80 (Scott, 1995). The path coefficients and significance levels in the structural model have shown in Figure 2.

${ }^{*} \mathrm{p}<0.05 ;{ }^{* *} \mathrm{p}<0.01 ;{ }^{* * *} \mathrm{p}<0.001$

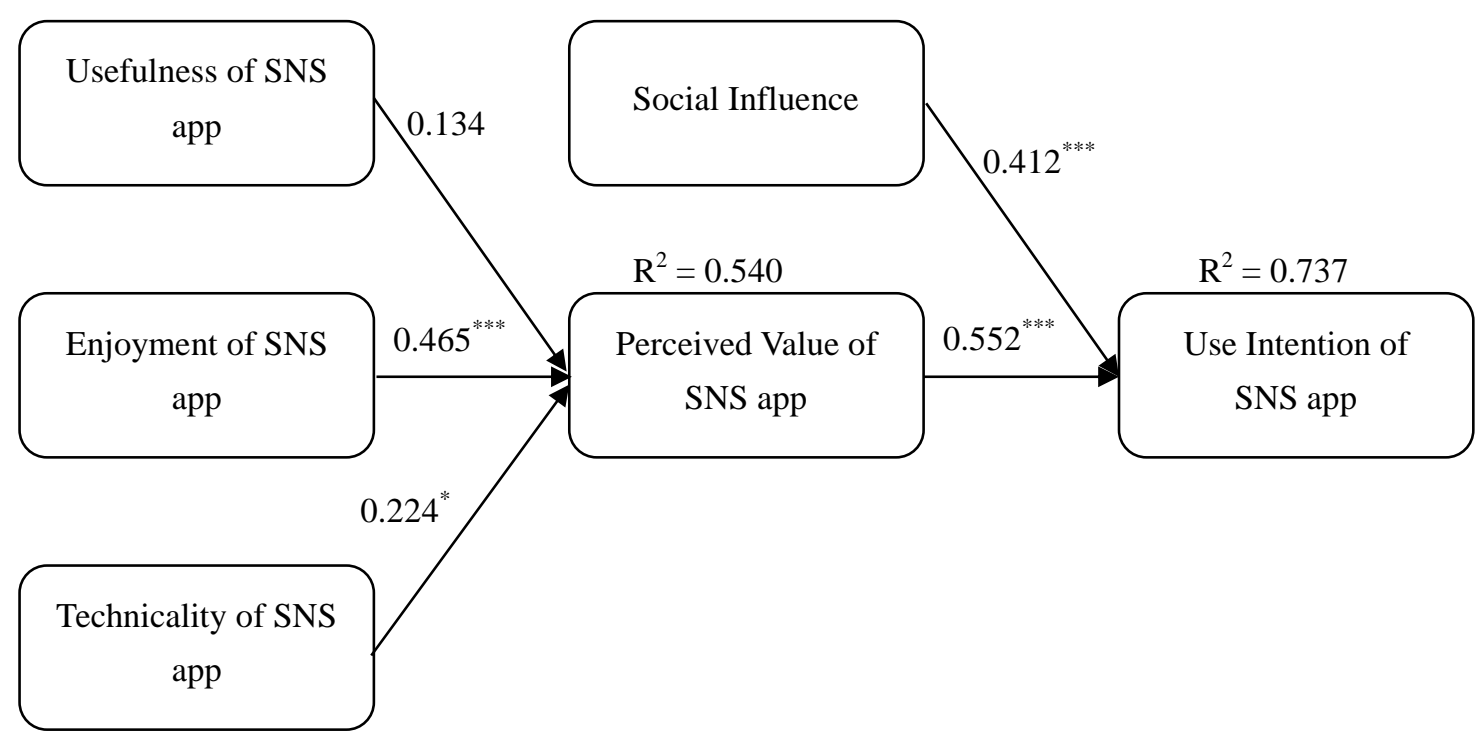

Figure 2. The structural model results

\subsection{Results and Discussion}

The empirical results, indicate that the enjoyment and technicality of SNS app positively influence the perceived value of the SNS app. H3 and H4 are supported. The results also show the enjoyment and good technicality of Facebook app can increase the perceived value of users. Therefore, the usefulness of the SNS app is not a significant factor for the perceived value of the app ( $\mathrm{p}=0.125, \mathrm{H} 2$ is unsupported). The possible explanations are as follows. The demographic statistics shows that there were more men than women, and the age of the users was mostly 15-30 years old. The analysis results are in accordance with the InsightXplorer ARO (access rating online) report and Taiwan Network Information Center report. The which show that Taiwan's Internet and mobile Internet users are mostly 15-34 years old (InsightXplorer, 2013; Taiwan Network Information Center [TWNIC], 2013a).Therefore, the users of this study can represent general users of Taiwan's Internet and mobile Internet groups.

According to a 2013 survey on wireless network usage, nearly 60\% of mobile device users download SNS app (TWNIC, 2013b). The data indicate that the majority of users will use SNSs through the mobile device app. However, in the context of mobile device use of Facebook, it is inevitable that users will access Facebook through the app because there is not enough to replace the app's mobile phone applications. However, users are most positive about the usefulness of the Facebook app (Average is 3.81 to 4.05). Nevertheless, it is not easy for the basic communication and the function use to enhance the user's perceived value of the Facebook app, which means that $\mathrm{H} 2$ is not supported.

The perceived value of SNS app and the social influence of the user experience are positively affect the use intention of the app. H1 and H5 are supported. The result shows that Facebook users are motivated by others to use the Facebook app. Users think that the overall evaluation of the Facebook app is positive, which and increases the use intention of the app.

\section{Conclusion and Implication}

Based on a literature review and an empirical analysis, this study found that the use intention of an SNS app is impacted by two positive factors: the user's perceived value of the app and social influence. These results are similar study of 
Nikou and Bouwman (2014). The perceived value of SNS app is positively affected by the users' enjoyment and the technicality of the app. When the SNS app can provide enjoyment or interest, it can enhance the overall value for the app experience. In addition, the SNS app has good reliability and is convenient. It also helps for save time for the user, which enhances the perceived value. However, the usefulness of the SNS app does not enhance the perceived value by users. A possible reason for such a result is that the SNS app is usually developed and provided by the SNS. There is no substitute, and the user has no choice. In addition, the SNS app must have communication features and functions for effective remote communication. The enjoyment and convenience cannot produce a corresponding positive effect, and users pay more attention to the perceived value and their satisfaction with the SNS app. An important goal for future development of SNS apps is effectively promoting use intention and recommending use to the community, friends, and family.

In addition to promoting academic knowledge on SNSs and mobile application research, this study provides the following practical implications for SNSs operators. Firstly, with the rapid growth of mobile network usage, users are more frequently using SNS apps. Thus, determining how to keep users using an SNS app is becoming a major test for industry. Secondly, more time is using the SNS app than the website version. Industry should focus more on enhancing the experience of mobile applications so that users are more willing to enter the virtual community through the app at any time, which would enhance the stickiness and activeness of users. Thirdly, social influence will help improve the usage of SNS apps. Companies can hold specific sharing actives to invite SNS members, which can attract potential users to join and use the SNS. However, excessive and annoying notifications may lead to a reduction in the user experience and poor evaluation of the SNS app. Finally, the SNS apps can be designed to provide more enjoyment. For example, the convenience and response speed of the user interface can enhance the technicality of users through instant feedback.

The limitations of this study are as follows. The results of the analysis may be limited to Facebook users. However, Facebook is the most popular SNS in Taiwan and has a high degree of utilization; the results may still be biased. Future studies may include users of other SNSs in the samples to examine the external validity of the study model. In addition, the focus of the study is on the use intention of the SNS app, but the experience of using a social version of the site's web pages may also affect users' perceptions of a particular SNS. Future research is needed to improve understanding of community user behavior.

\section{Reference}

Anckar, B., Carlsson, C., \& Walden, P. (2003). Factors affecting consumer adoption decision and intents in mobile commerce: Empirical insights. Proceedings of the 16th Bled eCommerce Conference. Bled, Slovenia.

Arnaboldi, V., Conti, M., \& Delmastro, F. (2014). CAMEO: A novel context-aware middleware for opportunistic mobile social networks. Pervasive and Mobile Computing, 11, 148-167. https://doi.org/10.1016/j.pmcj.2013.09.010

Bohn, A., Buchta, C., Hornik, K., \& Mair, P. (2014). Making friends and communicating on Facebook: Implications for the access to social capital. Social Networks, 37, 29-41. https://doi.org/10.1016/j.socnet.2013.11.003

Bollen, K. A. (1989). Structural equations with latent variables. New York: Wiley. https://doi.org/10.1002/9781118619179

Boyd, D. M., \& Ellison, N. B. (2007). Social network sites: Definition, history, and scholarship. Journal of Computer-Mediated Communication, 13(1), article 11. https://doi.org/10.1111/j.1083-6101.2007.00393.x

Browne, M. W., \& Cudeck, R. (1993). Alternative ways of assessing model fit. In K. A. Bollen, \& J. S. Long, (Eds.), Testing structural equation models (pp. 136-162). Newbury Park, CA: Sage.

Chaouali, W. (2016). Once a user, always a user: Enablers and inhibitors of continuance intention of mobile social networking sites. Telematics and Informatics, 33(4), 1022-1033. https://doi.org/10.1016/j.tele.2016.03.006

Cheung, C. M. K., Chiu, P. Y., \& Lee, M. K. O. (2011). Online social networks: Why do students use Facebook? Computer in Human Behavior, 27(4), 1337-1343. https://dx.doi.org/10.2307/325095110.1016/j.chb.2010.07.028

Davis, F. D. (1993). User acceptance of information technology: System characteristics, user perceptions and behavioral impacts. International Journal of Man-Machine Studies, 38(3), 475-487. https://doi.org/10.1006/imms.1993.1022

Deutsch, M., \& Gerard, H. B. (1955). A study of normative and informational social influences upon individual judgment. The Journal of Abnormal and Social Psychology, 51(3), 629-636. https://doi.org/10.1037/h0046408

Dholakia, U. M., Bagozzi, R. P., \& Pearo, L. K. (2004). A social influence model of consumer participation in networkand small-group-based virtual communities. International Journal of Research in Marketing, 21(3), 241-263. https://doi.org/10.1016/j.jiresmar.2003.12.004 
Dumrongsiri, N., \& Pornsakulvanich, V. (2010). Social networking sites in Thailand: Motives and predictors of university students' behaviors. International Journal of Innovation and Learning, 8(4), 427-444. https://doi.org/10.1504/IJIL.2010.035751

Fornell, C., \& Larcker, D. F. (1981). Evaluating structural equation models with unobservable variables and Measurement Error. Journal of Marketing Research, 18(1), 39-50. https://doi.org/10.2307/3151312

Greene, C. N., \& Organ, D. W. (1973). An evaluation of causal models linking the received role with job satisfaction. Administrative Science Quarterly, 18, 95-103. https://doi.org/10.2307/2391931

Hair, J. F., Black, B., Anderson, R. E., \& Tatham, R. L. (2005). Multivariate data analysis (6th ed.). New Jersey: Prentice Hall.

Harman, H. H. (1967). Modern factor analysis (2nd ed.). Chicago: University of Chicago Press.

Insight Xplorer (2013). InsightXplorer ARO announces Taiwan's frist smartphone usage behavior measurement report. Retrieved from March 23, 2013, http://www.insightxplorer.com/news/news_03_23_13.html/

Jahoda, M. (1959). Conformity and independence: A psychological analysis. Human Relations, 12(2), 99-120. https://doi.org/10.1177/001872675901200201

Kaplan, A. M. (2012). If you love something, let it go mobile: Mobile marketing and mobile social media 4x4. Business horizons, 55(2), 129-139. https://doi.org/10.1016/j.bushor.2011.10.009

Kelman, H. C. (1958). Compliance, identification, and internalization three processes of attitude change. The Journal of Conflict Resolution, 2(1), 51-60. https://doi.org/10.1177/002200275800200106

Kim, B., \& Han, I. (2009). What drives the adoption of mobile data services? An approach from a value perspective. Journal of Information Technology, 24, 34-45. https://doi.org/10.1057/jit.2008.28

Kim, H., Chan, H., \& Gupta, S. (2007). Value-Based adoption of mobile Internet: An empirical investigation. Decision Support System, 43, 111-126. https://doi.org/10.1016/j.dss.2005.05.009

López-Nicolás, C., Molina-Castillo, F. J., \& Bouwman, H. (2008). An assessment of advanced mobile services acceptance: Contributions from TAM and diffusion theory models. Information \& Management, 45(6), 359-364. https://doi.org/10.1016/j.im.2008.05.001

Lu, J., Yao, J. E., \& Yu, C. S. (2005). Personal innovativeness, social influences and adoption wireless Internet services via mobile technology. The Journal of Strategic Information Systems, 14(3), 245-268. https://doi.org/10.1016/j.jsis.2005.07.003

Moore, G. C., \& Benbasat, I. (1991). Development of an instrument to measure the perceptions of adopting an information technology innovation. Information Systems Research, 2(3), 192-222. https://doi.org/10.1287/isre.2.3.192

Mossholder, K. W., Bennett, N., Kemery, E. R., \& Wesolowski, M. A. (1998). Relationships between bases of power and work reactions: The mediational role of procedural justice. Journal of Management, 24(4), 533-552. https://doi.org/10.1177/014920639802400404

Ngai, E. W. T. (2007). Mobile commerce: Strategies, technologies, and applications. Decision Support Systems, 43(1), 1-2. https://doi.org/10.1016/j.dss.2005.05.002

Nikou, S., \& Bouwman, H. (2014). Ubiquitous use of mobile social network services. Telematics and Informatics, 31(3), 422-433. https://doi.org/10.1016/j.tele.2013.11.002

Nunnally, J. C. (1978). Psychometric Theory. New York: McGraw-Hill.

Podsakoff, P. M., \& Organ, D. W. (1986). Self-reports in organizational research: Problems and prospects. Journal of Management, 12, 531-544. https://doi.org/10.1177/014920638601200408

Podsakoff, P. M., MacKenzie, S. B., Lee, J. Y., \& Podsakoff, N. P. (2003). Common method biases in behavioral research: A critical review of the literature and recommended remedies. Journal of Applied Psychology, 88(5): 879-903. https://doi.org/10.1037/0021-9010.88.5.879

Podsakoff, P. M., Todor, W. D., Grover, R. A., \& Huber, V. L. (1984). Situational moderators of leader reward and punishment behaviors: Fact or fiction. Organizational Behavior and Human Performance, 34, 21-63. https://doi.org/10.1016/0030-5073(84)90036-9

Pornsakulvanich, V., \& Dumrongsiri, N. (2013). Internal and external influences on social networking site usage in Thailand. Computers in Human Behavior, 29(6), 2788-2795. https://doi.org/10.1016/j.chb.2013.07.016 
Scott, J. E. (1995). The measurement of information systems effectiveness: evaluating a measuring instrument. ACM SIGMIS Database, 26(1), 43-61. https://doi.org/10.1145/206476.206484

Sheth, J. N., Newman, B. I., \& Gross, B. L. (1991). Consumption values and market choices: Theory and applications. Southwestern publishing, Cincinnati, $\mathrm{OH}$.

Shin, D. H. (2009). A cross-national study of mobile Internet services: A comparison of U.S. and Korean mobile Internet users. Journal of Global Information Management, 17(4), 29-54. https://doi.org/10.4018/jgim.2009070902

Thaler, R. (1985). Mental accounting and consumer choice. Marketing Science, 4(3), 199-214. https://doi.org/10.1287/mksc.4.3.199

TWNIC (2013a). 2013 Taiwan broadband Internet usage survey. Retrieved from April 2013, http://www.twnic.net.tw/download/200307/20130926c.pdf

TWNIC (2013b). An investigation report on Taiwan's wireless network usage in 2013. Retrieved from December 31, 2013, http://www.twnic.net.tw/download/200307/20140109a.pdf

Udndata (2016). Facebook will help push the cross-border white paper. Retrieved from July 19, 2016, http://udndata.com/ndapp/udntag/finance/Article?origid=1838890\&ptname

Venkatesh, V., \& Brown, S. A. (2001). A longitudinal investigation of personal computers in homes: Adoption determinants and emerging challenges. MIS Quarterly, 25(1), 71-102. https://doi.org/10.2307/3250959

Venkatesh, V., \& Davis, F. D. (2000). A theoretical extension of the technology acceptance model: Four longitudinal field studies. Management Science, 46(2), 186-204. https://doi.org/10.1287/mnsc.46.2.186.11926

Venkatesh, V., Morris, M., Davis, G., \& Davis, F. (2003). User acceptance of information technology: Toward a unified view. MIS Quarterly, 27(3), 425-478. https://dx.doi.org/10.2307/325095110.2307/30036540

Wu, Y. L., Tao, Y. H., Li, C. P., Wang, S. Y., \& Chiu, C. Y. (2014). User-switching behavior in social network sites: A model perspective with drill-down analysis. Computers in Human Behavior, 33, 92-103. https://doi.org/10.1016/j.chb.2013.12.030

Zeithaml, V. A. (1988). Consumer perceptions of price, quality and value: a means-end model and synthesis of evidence. Journal of Marketing, 52(3), 2-22. https://doi.org/10.2307/1251446

Zheng, X., \& Lee, M. K. O. (2016). Excessive use of mobile social networking sites: Negative consequences on individuals. Computers in Human Behavior, 65, 65-76. https://doi.org/10.1016/j.chb.2016.08.011

\section{Copyrights}

Copyright for this article is retained by the author(s), with first publication rights granted to the journal.

This is an open-access article distributed under the terms and conditions of the Creative Commons Attribution license which permits unrestricted use, distribution, and reproduction in any medium, provided the original work is properly cited. 